\title{
The airway microvasculature and exercise induced asthma
}

\author{
Sandra D Anderson, Evangelia Daviskas
}

\begin{abstract}
It has been proposed that exercise induced asthma is a result of "rapid expansion of the blood volume of peribronchial plexi" (McFadden ER, Lancet 1990;335:880-3). This hypothesis proposes that the development of exercise induced asthma depends on the thermal gradient in the airways at the end of hyperpnoea. The events that result in exercise induced asthma are vasoconstriction and airway cooling followed by reactive hyperaemia. We agree that the airway microcirculation has the potential for contributing to the pathophysiology of exercise induced asthma. We do, however, question whether reactive hyperaemia, in response to airway cooling, is the mechanism whereby hyperpnoea provokes airways obstruction in asthmatic patients. Further, we question whether vasoconstriction accompanies dry air breathing and whether an abnormal temperature gradient and rapid rewarming of the airways are prerequisites for exercise induced asthma. From published experiments we conclude that dry air breathing is associated with vasodilatation and increase in airway blood flow rather than vasoconstriction and a decrease in blood flow to the airways. We propose that the stimulus for the increase in airway blood flow is an increase in osmolarity of the airway submucosa. This osmotic change is caused by the movement of water to the airway lumen in response to evaporative water loss during hyperpnoea. The increase in airway blood flow may occur directly or indirectly by the osmotic release of mediators. Exercise induced asthma is most likely to be due to the contraction of bronchial smooth muscle caused by the same mediators. Whether it is enhanced or inhibited by alterations in airway blood flow is not yet established in man.
\end{abstract}

(Thorax 1992;47:748-752)

Exercise induced asthma is the name used to describe the increase in airways resistance that follows vigorous exercise in most people with asthma. The severity of an attack of asthma provoked by exercise is determined by the level of ventilation reached and sustained during exercise and the water content of the inspired air. The stimulus for exercise induced asthma is the loss of water from the intrathoracic airways when they are bringing large volumes of air to alveolar conditions in a short time. ${ }^{1}$

Two major hypotheses have been put forward to explain the mechanism whereby water loss from the airways causes them to narrow. One hypothesis, put forward in $1984,{ }^{2}$ is that evaporative water loss causes a transient increase in osmolarity of the airway surface liquid. The increase in osmolarity is thought to stimulate the release of mediators that cause the airways to narrow, most likely by the contraction of bronchial smooth muscle. The second hypothesis, put forward in $1990,{ }^{3}$ suggests that exercise induced asthma is a mechanical event in which the airways are rapidly rewarmed by reactive hyperaemia of the bronchial circulation with subsequent oedema of the airway wall. This is thought to occur as a result of vasoconstriction in response to airway cooling during hyperpnoea.

Evidence for rapid rewarming and reactive hyperaemia of the airways as the critical event

The evidence for the theory that rapid rewarming with reactive hyperaemia of the airways is the critical event in the development of exercise induced asthma comes from a series of studies. The first, published in $1986,{ }^{4}$ showed that, when rapid rewarming of the airways was prevented in asthmatic subjects by giving them cold air to breathe during recovery, the fall in FEV (forced expiratory volume in one second) was reduced to less than $10 \%$. In the same study it was also shown that the airway response to four minutes of exercise during the breathing of cold air could be increased if the airways were rapidly rewarmed by giving the subjects hot, humid air to inhale during the recovery period. This happened in normal as well as asthmatic subjects. It was suggested that to induce obstruction a "thermal gradient seems to be necessary at the end of the challenge." A more rapid increase in airway temperature was shown to occur at the end of exercise in asthmatic subjects than in normal subjects. 
This finding was thought to reflect a hyperplastic bronchial circulation in the asthmatic subjects. ${ }^{5}$ The authors concluded that the development of obstruction "appears to consist of vasoconstriction and airway cooling during exercise followed by a rapid re-supply of heat when exercise ceases." Other evidence given in support of the rapid rewarming theory of exercise induced asthma comes from the relation of changes in intra-airway temperature to changes in $\mathrm{FEV}_{1}$, measured on a separate occasion, after repetitive exercise, ${ }^{6}$ and to increases in vascular volume produced by anti-shock trousers ${ }^{7}$ and by the rapid infusion of saline. ${ }^{8}$

Incriminating the bronchial circulation in the narrowing of the airways would be attractive, particularly as oedema serves to amplify the effects of bronchial smooth muscle contraction. $^{9-12}$ This hypothesis, however, raises questions about the prerequisites for the development of exercise induced asthma. Further, the experimental technique used in these studies raises the important question of whether a change in intra-airway temperature is an index of a change in airway blood flow.

This article addresses these questions. The argument is put forward that vasoconstriction and reactive hyperaemia in response to airway cooling are unlikely to be prerequisites for exercise induced asthma. Further, we suggest that the osmotic effects of evaporative water loss and mucosal dehydration may be the signal for an increase in bronchial blood flow. We conclude that it has yet to be established that increased bronchial blood flow plays a part in the airway narrowing of exercise induced asthma.

\section{Is vasoconstriction a prerequisite for exercise induced asthma and does it occur in response to airway cooling?} If vasoconstriction is a prerequisite for exercise induced asthma it must occur both when the inspired air is of subfreezing temperature and when it is as high as $80^{\circ} \mathrm{C}$-because airway narrowing follows hyperpnoea in the same individuals under both conditions. ${ }^{13}$ If asthmatics do develop vasoconstriction during hyperpnoea with dry air this would not only fulfil a requirement for reactive hyperaemia ${ }^{14}$ but also enhance the potential for airway drying and changes in osmolarity.

There is recent experimental evidence, however, both in animals ${ }^{15-17}$ and in man, ${ }^{18}$ that airway blood flow increases in response to the breathing of dry air over a wide range of temperatures. Agostoni et $a^{18}$ studied 50 patients having coronary artery bypass surgery, in which both the coronary circulation and the pulmonary circulation are bypassed. They found that when their patients were ventilated with dry air at a time when their airways were cool (about $27^{\circ} \mathrm{C}$ ) the airway blood flow was substantially greater (41 (SE $0.06) \mathrm{ml} / \mathrm{min}$ ) than it was while they were being ventilated with warm humid air (21.7 $(1.8) \mathrm{ml} / \mathrm{min})$. Several important questions remain unanswered. Does bronchial blood flow increase during hyperpnoea with dry air in individuals with asthma, and, if so, what is the time course of this response?

If the blood flow in asthmatic individuals increases in response to dry air-as it does in non-asthmatic subjects-at rest, reactive hyperaemia is unlikely to occur after exercise.

Does an abnormal temperature gradient need to exist for exercise induced asthma to occur?

There is evidence than neither rapid rewarming nor an abnormal temperature gradient in the airways needs to occur for an attack of asthma to be provoked by hyperpnoea. ${ }^{1319-21}$ Although an abnormally large temperature gradient is easily achieved by inspiring cold dry air during hyperpnoea, this clearly does not happen when hot dry air is inspired. For example, in the study of Deal et $a l^{13}$ the expired air temperature during exercise was $32.3^{\circ} \mathrm{C}$ and $37.1^{\circ} \mathrm{C}$ respectively when dry air of $25^{\circ} \mathrm{C}$ and $80^{\circ} \mathrm{C}$ was inspired during exercise and for four minutes after exercise. Under these conditions the severity of exercise induced asthma was not significantly different, the falls in $\mathrm{FEV}_{1}$ being $32 \%$ and $35 \%$. The temperature gradient between the mouth and the alveoli created by breathing air at $25^{\circ} \mathrm{C}$ was about $5^{\circ} \mathrm{C}$, whereas no gradient was created by breathing air of $80^{\circ} \mathrm{C}$ (on the assumption that the alveolar temperature is $\left.37^{\circ} \mathrm{C}\right)$. Although expired air temperature does not necessarily reflect local airway temperatures, experimental data ${ }^{5}$ do show that temperatures at the mouth are equal to, or lower than, those recorded in the lower airways.

Even though substantial heat is lost, owing to the evaporation of water, when hot air is inspired, the airways may not be cooled to a temperature lower than that normally recorded at rest during the breathing of ambient air. In support of this, Zawadaski et al $^{22}$ found that the expired air temperature was higher during hyperpnoea with hot air than it was when the same subjects inspired room air at resting ventilation! The asthmatic subjects had a fall in $\mathrm{FEV}_{1}$ of 0.5 (SE 0.07) 1 after hyperpnoea with hot air but no fall was reported after they had been resting. Furthermore, if an abnormal temperature gradient is all that is necessary to provoke airway narrowing then it should occur when inspired air conditions are changed from cold to hot during resting ventilation, but it does not. Thus for exercise induced asthma to occur there is no requirement for the airways either to be cooled to a temperature lower than that recorded under normal inspired air conditions or to develop a temperature gradient between exercise and the cessation of exercise.

To address the question of temperature gradient further, Ingenito et $a^{23}$ studied the bronchoconstrictor effect brought about by inspiring cold gas mixtures with different volume-heat capacities but the same water carrying capacity $\left(\mathrm{SF}_{6} \mathrm{O}_{2}\right.$ and $\left.\mathrm{HeO}_{2}\right)$. They found no relation between temperature gradient and heat loss or between total heat 
loss and airway response. They did, however, find a significant correlation between evaporative heat loss and change in lung function.

\section{Do the airways have to rewarm rapidly after exertion or hyperpnoea?}

It is well recognised that many people with asthma develop exercise induced asthma during exercise at a time when airway temperature is low and before rewarming could occur. ${ }^{24}$ This is particularly evident in patients with severe exercise induced asthma who exercise for eight minutes rather than four minutes. Several experiments have shown that the rate of rewarming may not necessarily determine the severity of the airway response. For example, when the condition of the air was cold during exercise and either cold or room temperature air was inspired during recovery, there was no difference in the maximum reduction in $\mathrm{FEV}_{1}$ (\% fall in $\mathrm{FEV}_{1} 20$ and 19 respectively). ${ }^{4}$ The thermal gradients and rate of rewarming would have been substantially different under these two conditions of recovery but the only difference was the time at which the fall in $\mathrm{FEV}_{1}$ occurred ( 15 versus five minutes after exercise). Similarly, no difference was found in the severity of exercise induced asthma in the study of Hahn et al ${ }^{19}$ when both exercise and recovery were in an environmental chamber set to $9^{\circ} \mathrm{C}$ or $36^{\circ} \mathrm{C}$. Further, the finding that rapid rewarming of the airways with saturated air at body temperature exacerbates exercise induced asthma ${ }^{4}$ was not confirmed in children. ${ }^{25}$ No differences were found in the airway responses when either cold dry air or fully saturated air at body temperature was inhaled during recovery from exercise. As in other studies, the duration of exercise appeared to be the important factor in obtaining a maximal airway response.

\section{Is a change in intra-airway temperature an index of airway perfusion?}

Intra-airway temperature measurements have shown that asthmatic subjects rewarm their airways more quickly than do normal subjects. ${ }^{45}$ This is thought to reflect a difference in the nature of the bronchial circulation, asthmatic individuals having a more hyperplastic circulation. When the expiratory flow rates are reduced during exercise induced asthma, however, the air inspired resides in the alveoli longer. The finding that the airways are more rapidly rewarmed after exercise that has provoked an attack of asthma may be explained simply by an increase in residence time of the gases in the airways. Rapid rewarming, rather than reflecting an increase in bronchial blood flow, may simply be a consequence of the increase in residence time and thus airway temperature produced by airway narrowing.

It has also been suggested that a rapid increase in the blood volume of the bronchial circulation reduces thermal gradients and thus reduces exercise induced asthma. One experiment has been the use of anti-shock trousers, which when activated give a sudden increase in the volume of blood in the airways. ${ }^{\text {? }}$
Suddenly increasing the blood volume in the airways attenuates the temperature gradient and reduces the airway response. In a second experiment intravenous infusion of about two litres of warm isotonic fluid was given. ${ }^{8}$ As plasma volume decreases rather than increases with short term exercise of high intensity these experiments do not mimic the effects of exercise. $^{2627}$ Further, a wide range of hormonal responses could be produced by an increase in vascular volume, making interpretation of these data difficult. ${ }^{26}$

The microvasculature and drugs used in the treatment and prevention of exercise induced asthma

The effects of many drugs in both the prevention and the reversal of exercise induced asthma are not in keeping with the theory of reactive hyperaemia of the bronchial circulation as the important event in exercise induced asthma. It is hard to explain the inhibitory effect of sodium cromoglycate on exercise induced asthma on the basis of any effect on vascular smooth muscle. Further, exercise induced asthma is reversed acutely in most patients with $\beta_{2}$ adrenoceptor agonists. Because many $\beta_{2}$ adrenoceptor agonists are potent vasodilators, a rapid reversal of airway narrowing would not be expected if the cause of this narrowing were vascular engorgement.

It has been suggested that "when given after exercise beta agonists could speed the removal of oedema." ${ }^{3}$ This suggestion was based on the action of the $\beta_{2}$ adrenoceptor agonists in inhibiting histamine induced oedema in the skin. ${ }^{28}$ The role of $\beta_{2}$ adrenoceptor agonists in decreasing microvascular permeability and preventing oedema is well known. There is no evidence, however, that these drugs reverse oedema once it has occurred, ${ }^{28}$ and this is unlikely to be their mode of action in reversing exercise induced asthma. By contrast ephedrine, a potent vasoconstrictor, might be expected to be a powerful preventive agent in exercise induced asthma when given orally, but it is not. ${ }^{29}$ Theophylline, which is thought to prevent extravasation from blood vessels and reduce airway oedema, ${ }^{30}$ has only a partially preventive effect in exercise induced asthma, even when given intravenously during exercise. ${ }^{31}$ The drugs that act to relax vascular smooth muscle but also reduce exercise induced asthma (for example, calcium antagonists, nitrates, $\alpha$ receptor antagonists) may act by increasing blood flow, thereby improving water delivery and enhancing the clearance of mediators rather than reducing temperature gradients.

\section{What is the signal for an increase in bronchial blood flow?}

On the basis of the experimental evidence on airway temperature and changes in airway blood flow ${ }^{15-1832}$ airway drying appears to be associated with an increase in airway blood flow. We think that an increase in osmolarity of the airway surface liquid, epithelial cells, and air- 
way submucosa subsequent to airway drying acts as the stimulus to this increase in airway blood flow. We have estimated that the osmolarity of the airway surface liquid may rise transiently to as much as $900 \mathrm{mOsmol}$ during exercise. ${ }^{24}$ This high osmolarity would act as a potent stimulus for water to enter the airway lumen from the epithelial cells and from the submucosa either via the paracellular pathway or via the epithelial cells. If the water lost from the airway surface liquid layer by evaporation is replaced by water from epithelial cells, and if the epithelial cell volume is replaced by water coming from the submucosa, ${ }^{33}$ there should be an increase in the concentration of ions surrounding the blood vessels. We propose that, in response to airway drying, there is a small increase in osmolarity in the submucosa of the airways or epithelial cells, and this in some way acts as the stimulus for the airway blood flow to increase for the delivery of more water.

\section{Evidence supporting osmolarity as the stimulus for increased bronchial blood flow}

Deffebach et al $^{34}$ showed that vasodilatation of the tracheal circulation occurred in response to hypertonic, but not isotonic, solutions perfusing the trachea. This indicates that vasodilatation and an increase in blood flow can occur independently of thermal events, and as a result of increased osmolarity of the perfusion fluid. The blood flow to skeletal muscle has also been shown to increase in response to very small changes in osmolarity $(10-20 \mathrm{mOsmol})$ brought about by the generation of lactate. ${ }^{35}$

Even though blood flow may increase and water may diffuse rapidly through the circulation, the demands for it during hyperpnoea may outstrip the supply. Studies by Tabka et $a l^{36}$ show the inability of the human airways to maintain a fluid balance during the breathing of warm dry air. They showed that during 15 minutes of exercise at 50 watts breathing dry air of $28^{\circ} \mathrm{C}$, the concentration of expired water decreased in both normal and asthmatic subjects to less than $29 \mathrm{mg} / \mathrm{l}$, which was less than $80 \%$ relative humidity. In the normal subjects the concentration of expired water was restored to normal within five minutes, whereas in the asthmatic subjects it was not. The authors suggested that this would be in keeping with dehydration and hyperosmolarity of the airway mucosa. These findings could be explained by insufficient delivery of water during exercise in both the normal and the asthmatic subjects. If this is the case, then this water delivery appears to be still reduced during recovery. There is pathological evidence that the return of water is insufficient to replace the water lost by evaporation during mechanical ventilation in man. ${ }^{37} 38$ Mathematical models of heat and water loss from the airways also confirm the potential for substantial loss of water from below the pharynx, even when temperate air is inspired at moderate ventilation rates. ${ }^{39} 40$

From the intra-airway temperature measurements given by Gilbert et $a l^{5}$ an analysis of the magnitude of water lost from the trachea to the fifth generation has been made. ${ }^{24}$ This analysis showed that the airway surface could become dehydrated within a few minutes even if the water is lost at only $1 \mathrm{mg} / \mathrm{l}$. Dehydration of the trachea could occur very quickly as less than $68 \mathrm{mg}$ of airway surface liquid is thought to cover it. Even the epithelial cells could be significantly dehydrated within five minutes. Gilbert et $a l^{5}$ were unable to conclude that dehydration and an increase in osmolarity of the airway surface liquid were important. The reason for this was that they inadvertently calculated the volume of water lost as a proportion of the volume available over 17 generations of airways rather than as a proportion of the volume in the five generations over which the loss occurred.

\section{Mechanisms whereby an increase in osmolarity in the submucosa increases airway blood flow}

Increases in osmolarity cause mast cells to release histamine. ${ }^{41}$ In addition to producing its well recognised effect in contracting bronchial smooth muscle the histamine could also act on receptors on the precapillary sphincters causing relaxation and an increase in blood flow. ${ }^{42}$ If an increase in osmolarity of the submucosa does cause an increase in airway blood flow and a movement of fluid into the interstitial space, this may not necessarily cause oedema, but could merely lead to a rapid opening of junctions between endothelial cells. ${ }^{43}$ In these circumstances the osmotic gradient may be quickly reduced.

In addition to increasing blood flow, possibly the increases in osmolarity also cause leakage from the airway microvasculature. The mediator for this may be one or more of the sensory neuropeptides. ${ }^{44}$ Evidence for this comes from experiments in rats, in which an increase in vascular permeability occurred with exposure to hyperosmolar sodium chloride. ${ }^{44}$ This effect could be diminished by pretreatment with capsaicin, increased by pretreatment with phosphoramadon, and simulated by giving substance $P$.

If increased airway osmolarity, rather than airway cooling, is the stimulus for increased airway blood flow, this would serve to explain several observations about exercise induced asthma. For example, it would explain why both intensity and duration of hyperpnoea are important determinants of the response. ${ }^{4647}$ The longer and more intense the hyperpnoea the greater is the number of airways that will become hyperosmolar. It would also explain why a temperature gradient or abnormal cooling of the airways is not necessary for the development of exercise induced asthma. ${ }^{1319-21}$ The beneficial effect on exercise induced asthma of many of the drugs that are vasodilators can be explained on the basis of improving water delivery to the airways. Further, the refractory period could be explained by improved water delivery to the airways caused by a persistent increase in airway blood flow at the time of repeated challenge. The delay in the airway response observed in many subjects until after 
the cessation of hyperpnoea ${ }^{48}$ may in part be due to the fact that cooling is an inhibitory rather than an excitatory stimulus. ${ }^{50}$

It is well known from studies using hyperosmolar aerosols that the airways of individuals with asthma narrow in response to an increase in osmolarity, and this is most likely to be a result of bronchial smooth muscle contraction. ${ }^{51}$ We have previously proposed ${ }^{2}$ that the osmolarity of the airway surface liquid increases in response to the evaporative water loss accompanying dry air breathing, and that exercise induced asthma is a consequence of the mediators released in response to this osmotic change. We now propose that an increase in osmolarity of the airway submucosa, through either direct or indirect effects, is the stimulus to the increase in airway blood flow observed during dry air breathing. Whether this increase in flow contributes in any way to the airway narrowing that follows exercise or hyperventilation in man has still to be established.

1 Anderson SD. Exercise-induced asthma: stimulus, mechanism and management. In: Barnes PJ, Rodger I, Thomson NC, eds. Asthma, basic mechanisms and clinical management. London: Academic Press, 1988:503-22.

2 Anderson SD. Is there a unifying hypothesis for exerciseinduced asthma? J Allergy Clin Immunol 1984;73:660-5.

3 McFadden ER. Hypothesis: exercise-induced asthma as a vascular phenomenon. Lancet 1990;335:880-2.

4 McFadden ER, Lenner KA, Strohl KP. Postexertional airway rewarming and thermally induced asthma. J Clin Invest 1986;78:18-25.

5 Gilbert IA, Fouke JM, McFadden ER. Heat and water flux in the intrathoracic airways and exercise-induced asthma. J Appl Physiol 1987;63:1681-91.

6 Gilbert IA, Fouke JM, McFadden ER. The effect of repetitive exercise on airway temperatures. Am Rev Respir Dis 1990;142:826-31.

7 Gilbert IA, Regnard J, Lenner KA, Nelson JA, McFadden ER. Intrathoracic airstream temperatures during acute expansions of thoracic blood volume. Clin Sci 1991, 81:655-61.

8 Gilbert IA, Winslow CJ, Lenner KA, Nelson JA McFadden ER. Pulmonary obstruction in normals and asthmatics following intravenous fluid infusions to induce bronchial vasocongestion [abstract]. Am Rev Respir Dis 1988;139:A498.

9 Moreno RH, Hogg JC, Paré PD. Mechanics of airway narrowing. Am Rev Respir Dis 1986;133:1171-80.

10 Csete ME, Abraham WM, Wanner A. Vasomotion influences airflow in peripheral airways. Am Rev Respir Dis 1990;141:1409-13.

11 Blosser S, Mitzner W, Wagner EM. Effects of increased bronchial blood flow on airway resistance [abstract] FASEB J 1990;4:A289.

12 Corfield DR, Hanafi Z, Webber SE, Widdicombe JG. Changes in tracheal mucosal thickness and blood flow in sheep. J Appl Physiol 1991;71:1282-8.

13 Deal EC, McFadden ER, Ingram RH, Strauss RH, Jaege $\mathrm{JJ}$. Role of respiratory heat exchange in production of exercise-induced asthma. J Appl Physiol:Respirat Environ Exercise Physiol 1979;46:467-75.

14 Guyton AC. Textbook of medical physiology. 6th ed. Philadelphia: Saunders, 1981:354.

15 Baile EM, Dahlby RW, Wiggs BR, Parsons GH, Paré PD. Effect of cold and warm dry air hyperventilation on canine airway blood flow. J Appl Physiol 1987;62:526-32.

16 Salonen RO, Webber SE, Deffebach ME, Widdicombe JG Tracheal vascular and smooth muscle responses to air temperature and humidity in dogs. J Appl Physiol 1991 71:50-9.

17 Parsons GH, Pare PD, White DA, Baile EM. Airway blood flow response to eucapnic dry air hyperventilation in sheep. J Appl Physiol 1989;66:1443-7.

18 Agostoni $P$, Arena V, Doria E, Susini G. Inspired gas relative humidity affects systemic to pulmonary bronchial blood flow in humans. Chest 1990;97:1377-80.

19 Hahn A, Anderson SD, Morton AR, Black JL, Fitch KD. A re-interpretation of the effect of temperature and wate content of the inspired air in exercise-induced asthma. $A m$ Rev Respir Dis 1984;130:575-9.

20 Anderson SD, Schoeffel RE, Black JL, Daviskas E. Airway cooling as the stimulus to exercise-induced asthma. A reevaluation. Eur J Respir Dis 1985;67:20-30.

21 Eschenbacher WL, Sheppard D. Respiratory heat loss is not the sole stimulus for bronchoconstriction induced by isocapnic hyperpnea with dry air. Am Rev Respir Dis 1985; 131:894-901.
22 Zawadski DK, Lenner KA, McFadden ER. Comparison of intraairway temperatures in normal and asthmatic subjects after hyperpnea with hot, cold, and ambient air Am Rev Respir Dis 1988;138:1553-8.

23 Ingenito E, Solway J, Lafleur J, Lombardo A, Drazen JM Pichurko B. Dissociation of temperature-gradient and evaporative heat loss during cold gas hyperventilation in cold-induced asthma. Am Rev Respir Dis 1988;138:540-6.

24 Anderson SD, Daviskas E, Smith CM. Exercise-induced asthma: a difference in opinion regarding the stimulus. Allergy Proc 1989;10:215-26.

25 Smith CM, Anderson SD, Walsh S, McElrea MS. An investigation of the effects of heat and water exchange in the recovery period after exercise in children with asthma. Am Rev Respir Dis 1989;140:598-605.

26 Convertino VA, Keil LC, Bernauer EM, Greenleaf JE. Plasma volume, osmolality, vasopressin, and renin activity during graded exercise in man. $J$ Appl Physiol 1981;50: 123-8.

27 Nose H, Takamata A, Mack GW, Oda Y, Okuno T, Kang $\mathrm{DH}$, et al. Water and electrolyte balance in the vascular space during graded exercise in humans. $J$ Appl Physiol 1991;70:2757-62.

28 Basran GS, Paul W, Morley J, Turner-Warwick $M$ Adrenoceptor agonist inhibition of histamine-induced cutaneous response in man. Br J Dermatol 1982;107(suppl 23):140-2.

29 Bierman CW, Pierson WE, Shapiro GG. Exercise-induced asthma. Pharmacological assessment of single drugs and drug combinations. JAMA 1975;234:295-8.

30 Persson CG. Leakage of macromolecules from the tracheobronchial microcirculation. Am Rev Respir Dis 1987;135 S71-5.

31 Laursen I.C, Johannesson N, Weeke B. Effects of enprophylline and theophylline on exercise-induced asthma. Allergy 1985;40:506-9.

32 Baile EM, Godden DJ, Paré PD. Mechanism for increase in tracheobronchial blood flow induced by hyperventilation of dry air in dogs. J Appl Physiol 1990;68:105-12.

33 Yankaskas JR, Gatzy JT, Boucher RC. Effects of raised osmolarity on canine tracheal epithelial ion transport function. J Appl Physiol 1987;62:2241-5.

34 Deffebach ME, Salonen RO, Webber SE, Widdicombe JG. Cold and hyperosmolar fluids in canine trachea: vascular and smooth muscle tone and albumin flux. J Appl Physio 1989;66:1309-15.

35 Lundvall J. Tissue hyperosmolarity as a mediator of vasodilatation and transcapillary fluid flux in exercising skeletal muscle. Acta Physiol Scand 1972; suppl 379:1-137.

36 Tabka Z, Ben Jebria A, Vergeret J, Guenard H. Effect of dry warm air on respiratory water loss in children with exercise-induced asthma. Chest 1988;94:81-6.

37 Burton JDK. Effects of dry anaesthetic gases on the res piratory mucous membrane. Lancet $1962 ; \mathrm{i}: 235-8$.

38 Chalon J, Loew DAY, Malebranche J. Effects of dry anesthetic gases on tracheobronchial ciliated epithelium. Anesthesiology 1972;37:338-42.

39 Daviskas E, Gonda I, Anderson SD. Mathematical modeling of heat and water transport in human respiratory tract. J Appl Physiol 1990;69:362-72.

40 Daviskas E, Gonda I, Anderson SD. Local airway heat and water vapour losses. Respir Physiol 1991;84:115-32.

41 Eggleston PA, Kagey-Sobotka A, Lichtenstein LM. A comparison of the osmotic activation of basophils and human lung mast cells. Am Rev Respir Dis 1987;135: 1043-8.

42 Long WM, Sprung CL, El Fawal H, Yerger LD, Eyre $P$, Abraham WM, et al. Effects of histamine on bronchial artery blood flow and bronchomotor tone. J Appl Physio 1985;59:254-61.

43 Persson CGA, Eriefalt I, Alkner U, Baumgarten C, Greiff L, Gustafsson B, et al. Plasma exudation as a first line respiratory mucosal defence. Clin Exp Allergy 1991;21. 17-24.

44 Umeno E, McDonald DM, Nadel JA. Hypertonic saline increases vascular permeability in the rat trachea by producing neurogenic inflammation. J Clin Invest 1990; 851:1905-8.

45 Pisarri TE, Jonzon A, Coleridge HM, Coleridge JCG. Intravenous injection of hypertonic $\mathrm{NaCl}$ solution stimulates pulmonary C-fibers in dogs. Am J Physiol 1991 260[Heart Circ Physiol 29]:H1522-30.

46 Silverman M, Anderson SD. Standardization of exercise tests in asthmatic children. Arch Dis Child 1972;47:882-9.

47 Assoufi BK, Dally MB, Newman-Taylor AJ, Denison DM Cold air tests: a simplified standard method for airway reactivity. Bull Eur Physiopathol Respir 1986;22:349-57.

48 Blackie SP, Hilliam C, Village R, Paré PD. The time course of bronchoconstriction in asthmatics during and after isocapnic hyperventilation. Am Rev Respir Dis 1990;142: 1133-6.

49 Smith CM, Anderson SD. A comparison between the airway response to isocapnic hyperventilation and hypertonic saline in subjects with asthma. Eur Respir J 1989;2:36-43.

50 Freed AN, Fuller SD, Stream CE. Transient airway cooling modulates dry-air induced and hypertonic aerosolinduced bronchoconstriction. Am Rev Respir Dis 1991; 144:358-62.

51 Smith CM, Anderson SD. Inhalation provocation tests using nonisotonic aerosols. J Allergy Clin Immunol 1989; 84:781-90. 